\title{
JoÃo GUIMARÃES ROSA, TRADUTOR DE O ÚLTIMO DOS MAÇARICOS, DE FRED BODSWORTH
}

\author{
JoÃo GUIMARÃES RoSA, TRANSLATOR OF LAST OF THE CURLEWS BY \\ FRED BODSWORTH
}

\author{
(a) \\ Pedro Guilherme Bastos MENEZES ${ }^{\mathrm{i}}$ \\ Mestrando em Literatura (POSLIT) \\ Universidade de Brasília (UnB) \\ Brasília, Distrito Federal, Brasil \\ pgbmenezes@gmail.com
}

\begin{abstract}
Resumo: O presente artigo tem dois objetivos concernentes à tradução, por João Guimarães Rosa, do romance condensado Last of the Curlews (1954), do escritor canadense Fred Bodsworth, sob o título de $O$ Último dos Maçaricos (1958). O primeiro diz respeito ao contexto da tradução, e busca compreender certos aspectos do processo tradutório, desde a motivação para fazê-lo até o uso de material bibliográfico técnico de ornitologia como apoio. O segundo se refere ao texto traduzido, e procura realizar descrição e análise de determinados trechos que demonstram a preocupação do escritor mineiro em produzir, em português, uma obra relevante poeticamente, ainda que a linguagem do original em inglês seja diversa daquela de radicalidade que caracterizou a obra própria de Rosa. Para alcançar tais fins, são utilizados - além do original e da tradução - documentos, depoimentos de terceiros e correspondência com seus tradutores italiano e alemão.

Palavras-chave: João Guimarães Rosa. Fred Bodsworth. Tradução. O Último dos Maçaricos. Last of the Curlews.

Abstract: This article concerns João Guimarães Rosa's translation of the condensed novel Last of the Curlews (1954), from Canadian writer Fred Bodsworth, entitled O Último dos Maçaricos (1958). In the first place, we describe the context in which the translation was made as well as certain aspects of the process itself, such as the motivation behind it and the use of ornithological books by the translator. Then, some passages of the novel are analyzed in order to corroborate the conceivable effort undertaken by Rosa to write a poetically relevant text, even though the style of the novel does not match that of Rosa's own oeuvre. Other texts besides the novel are used to achieve these objectives, such as documents, statements from close friends and the correspondence between Rosa and his Italian and German translators.
\end{abstract}

Keywords: João Guimarães Rosa. Fred Bodsworth. Translation. O Último dos Maçaricos. Last of the Curlews.

Cada pássaro que voa, cada espécie, tem voo diferente. Quero descobrir o que caracteriza o voo de cada pássaro, em cada momento. Não há nada igual neste mundo. (trecho de "entrevista" concedida por João Guimarães Rosa a Pedro Bloch, em 15/06/1963) ii $^{\mathrm{ii}}$

\section{Esclarecimentos}

uito se sabe sobre João Guimarães Rosa autor (de Sagarana, Grande sertão:
veredas, Corpo de Baile, entre outros). São notórios também seu fascínio por
idiomas e os desafios que travaram os tradutores de sua obra. Mas de Rosa 
tradutor, ele próprio versando textos inteiros de uma língua a outra, pode-se dizer que ainda pouco se sabe ou se discute. Talvez pela dimensão de sua obra própria em comparação com aquilo que traduziu, o que ainda é incerto e cujas informações se espalham escassamente em revistas, depoimentos e documentos. ${ }^{\text {iii }}$

Este artigo tem por tema uma dessas traduções, o romance condensado Last of the Curlews (1954), do canadense Fred Bodsworth, intitulado O Último dos Maçaricos. Primeiramente, a fim de esclarecer o contexto em que tal empreendimento foi realizado, serão utilizados documentos, declarações de terceiros, além de fatos biográficos do escritor mineiro. Em seguida, serão feitas análises poéticas de trechos do texto traduzido em cotejo com o original, intercalando tal procedimento com passagens de cartas de Rosa a seus próprios tradutores, a fim de encontrar paralelos entre as orientações dadas a eles - e, por extensão, entre suas perspectivas acerca da tradução - e suas decisões próprias.

Com esse objetivo, foram norteadores os procedimentos de pesquisa desenvolvidos por Antoine Berman em seu texto Esboço de um Método, contido em Pour une critique des traductions: John Donne (1995). Tais processos não foram tomados como um método

58 passível de aplicação pura e simples, visto que o autor mesmo destaca a provisoriedade de seu proceder. Foram tratados, em realidade, como diretrizes das quais se tirou proveito quando se apresentaram fecundas no caso específico d'O Último dos Maçaricos, dadas as peculiaridades do fazer literário de João Guimarães Rosa, de sua inabitual iniciativa tradutória e da igualmente atípica correspondência que manteve com seus tradutores.

De Berman, foram úteis para o esclarecimento do contexto da tradução suas considerações referentes à "procura do tradutor", às posições "tradutória", "linguística" e "de escrita", assim como ao "projeto de tradução" e ao "horizonte do tradutor". No que se refere à descrição e análise, foram importantes seus apontamentos concernentes ao ordenamento das leituras (primeiramente a tradução, em seguida o original, para, então, cotejá-los) e suas estratégias de execução, isto é: o que ele denomina "olhar receptivo" e identificação de zonas "problemáticas" e "miraculosas" na tradução, assim como a seleção de exemplos estilísticos e apontamento de "zonas significantes" no original.

\section{Contexto}

Em 1958, é publicada no volume IV da Biblioteca de Seleções da Reader's Digest (editora Ypiranga, Rio de Janeiro) a versão condensada do romance Last of the Curlews, com tradução de João Guimarães Rosa, sob o título $O$ Último dos Maçaricos. O texto reduzido foi 
primeiramente publicado pela Reader's Digest norte-americana em 1955. Ao traduzi-lo, porém, Rosa não se limitou apenas à edição mais curta; em vez disso, importou dos EUA a versão completa, como relata Manuel Bandeira, em crônica de 22 de janeiro de 1961, ao falar do perfeccionismo do escritor mineiro:

Eu sabia que era assim com Rosa. Sabia do que se passou com ele quando foi convidado a traduzir para Seleções um romance condensado. Era a história de um pássaro. Rosa mandou vir dos Estados Unidos o romance completo. Mandou vir também tratados de ornitologia. Fez a tradução, reescreveu-a cinco vezes. No fim saiu obra perfeita, coisa que não era no original. Mas Rosa gastou muito mais do que ganhou. (BANDEIRA, 1966, p. 319-20)

O contexto exato de como a negociação se deu para que Rosa traduzisse o romance deve ser melhor investigado, assim como o processo de tradução em si. De toda forma, alguns depoimentos e trocas de cartas permitem entrever uma movimentação do escritor na direção de obter materiais no campo da ornitologia um ano antes de a tradução ser publicada. Josué Montello, em Diário da Manhã, conta acerca de uma carta de Rosa recebida por ele em maio de 1957:

Recebi longa carta de Guimarães Rosa, com este pedido: "Preciso de informações sobre aves europeias, em português, para um estudo que estou fazendo, e queria ver se você conseguia aí, para mim: Catálogo das aves de Portugal, publicado por A. F. Seabra, em 1911; Aves da península, por Paulino de Oliveira, e Catálogo das aves, por Dom Carlos de Bragança”. (MONTELLO, 1998, p. 434)

Tratar-se-ia de material para a feitura da tradução? É possível pensar que sim, visto que, poliglota que era, o pedido para bibliografia sobre aves europeias especificamente em português chama a atenção. Pode-se conjecturar que Rosa estava à procura, talvez, de vocabulário específico já consolidado, sendo essa mesma uma orientação a seus tradutores, como em carta ao seu tradutor alemão, Curt Meyer-Clason:

O LOBUM = o cheiro do lobo | Wolfsgestank ou Wolfsstinkerei (Deve haver uma palavra alemã para isso, na rica linguagem dos caçadores) (ROSA, 2003, p. 341) Guaxe-do-rabo-amarelo: der Kamik (Ave, das Icteridae: Cacicus haemorrhous, Lin) (O nome "der Kasik" [...] já está consagrado na literatura científica alemã) (ibidem, p. 248)

É interessante notar ainda a importância do contato feito por Rosa com o ornitólogo alemão naturalizado brasileiro Helmuth Sick, o qual colabora na tradução e adaptação dos nomes de aves a serem vertidos para o alemão no Grande sertão: veredas e no Corpo de Baile (ibidem, pp. 159, 168 e 176). Tal fato demonstra que Rosa não prescindia do conhecimento 
especializado e em primeira mão, ainda que ele próprio fosse um arguto observador e conhecedor de aves. ${ }^{\text {iv }}$

Além do pedido específico a Josué Montello por livros técnicos em português, o ano da carta, 1957, coincide com o de outro pedido, este feito a Mário Calábria - colega de carreira diplomática - para que procurasse publicações referentes a pássaros norte-americanos e canadenses, em especial sobre o curlew (maçarico), ave protagonista do romance traduzido. ${ }^{\vee}$ Mário Calábria contribuiu ainda com a tradução do livro por meio de leituras e críticas prévias à publicação, como conta o escritor mineiro:

\footnotetext{
Vou contar-lhe uma coisa. Eu, uma vez, perpetrei a tradução, do inglês para o português, de uma história de passarinho (The Last of the Curlews/O último dos maçaricos). Pois bem, hoje sei que não teria conseguido fazê-la com nem ao menos $50 \%$ de resultado e efeito, não fosse a cooperação afetuosa de Mário Calábria, emprestando-me vivo seu "dispositivo ultra-verificador", interpretador, e seus olhos do espírito. (ibidem, p. 165)
}

Há, ademais, no Arquivo João Guimarães Rosa, o original da tradução - “Conjunto de 6034 páginas datiloscritas contendo tradução condensada do livro de C. Fred Bodsworth, 'Last of the Curlews', realizada por João Guimarães Rosa. Assinado por este.”vi - cuja datação corresponde ao mesmo ano dos dois pedidos já citados: “de 5/1957 a 6/1957”. Como já exposto, a tradução seria publicada no ano seguinte, em 1958.

Observando a obra de Rosa como um todo, em que a tradução não é senão uma mínima parte - não ignorando, evidentemente, a fundamental importância que têm as línguas estrangeiras e os aproveitamentos linguísticos -, faz-se notar um certo aspecto circunstancial no que se refere ao seu fazer tradutório, tanto mais somada tal ponderação ao tom do relato acima: "Eu, uma vez, perpetrei a tradução [...]". Qual teria sido, então, a motivação do escritor para traduzir um romance condensado (ao todo, 36 páginas), com objetivo de publicação, visto que não se tratava de uma atividade paralela e constante?

Vale a pena lembrar que, em 1958 (data da publicação da tradução) e 1957 (ano em que deve tê-la efetuado, de acordo com os pedidos por material especializado e o original datiloscrito), Rosa já era um escritor de todo maduro e em breve começaria a ser traduzido para outros idiomas, tendo publicado no ano anterior, 1956, tanto Grande sertão: veredas quanto Corpo de Baile. A questão torna-se ainda mais curiosa ao se notar que Last of the Curlews, em sua língua original, pouco tem a ver com a prosa engendrada pelo próprio escritor: a de invenção linguística, seja a partir de criação de novos vocábulos e de 
empréstimos frente a outras línguas, seja a partir de reutilização de arcaísmos e de aproveitamento da fala do sertanejo.

O romance condensado é dividido em 13 episódios entremeados por relatos de boletins científicos que atestam o progressivo desaparecimento do maçarico-esquimó (Eskimo curlew, Numenius borealis) nos séculos XIX e XX, devido à caça humana predatória. É contada a estória de um exemplar da espécie durante a migração de acasalamento, à procura de uma fêmea para se reproduzir. Depois de muito custo e peripécias, o pássaro enfim encontra sua parceira. Pouco depois, porém, no fim do livro, ela é alvejada por arma de fogo e morta - tornando-se ele, virtualmente, o último de sua sorte.

É possível que o interesse de Rosa por pássaros e pela natureza em geral - o qual se pode depreender de sua correspondência, como se verá a seguir ${ }^{\mathrm{vii}}$ - tenha-o feito se decidir por traduzir o romance, tendo em vista a disparidade do texto em inglês e de sua obra própria no que se refere à estética? A seguir, a citação de uma carta de 1939 a seu irmão, enviada de Hamburgo, na Alemanha, em trecho que facilmente se confundiria com algum outro de $O$ Último dos Maçaricos:

As cegonhas, que tinham passado o inverno nos países do Mediterrâneo - no Egito, na Síria, na Líbia - já regressaram aos seus velhos ninhos, instalados junto às chaminés dos chalés. O rouxinol canta, a noite inteira, nos galhos dos castanheirosbravos, onde esplendem, em candelabros minúsculos, os cachos das flores alvíssimas. (ROSA, 2014, p. 247)

Em carta a seu tradutor alemão, ao fornecer informações sobre uma ave específica e criticar uma opção tradutória, ficam evidenciados seus conhecimentos de ornitologia, tanto no que se refere às nomenclaturas científica e popular quanto no tocante aos hábitos dos animais:

\footnotetext{
ARIRI $=$ iriri, irerê $=$ "Ave da família dos Anatídeos (Dendrocygna viduata), também chamada marreca-piadeira, marreca-viúva, chega-e-vira." (Em inglês: the white-faced duck.) (ROSA, op. cit., p. 206)

[...]

O que há é que, quando um pássaro voa imediatamente atrás de outro, o deslocamento de ar produzido pelo primeiro dá sustentação ou ajuda o apoio do segundo, fisicamente, poupando-lhe esforço. Por isso é que as aves migradoras voam em formação angular, com as mais fortes à frente, seguidas pelos mais jovens ou fracos, em ordem decrescente. Quando um dos da frente se sente cansado, passa para trás, trocando de lugar, e então repousa - voando dormindo. (ibidem, p. 345, grifos no original)
}

Este trabalho não pretende, com a exposição acima, afirmar que a escolha por parte de Rosa para empreender a tradução de $O$ Último dos Maçaricos tenha sido puramente afetiva ou 
de engajamento político pela causa sustentada pelo romance. ${ }^{\text {viii }}$ Isso vai contra muito o que diz o autor acerca de seu fazer literário. Na correspondência com seu tradutor italiano, Edoardo Bizzarri, a respeito da referencialidade em seus livros, faz assertivas como: "Mas, enfim, não creio que esses nomes de plantas e árvores, à guisa de documentação, sejam importantes. Andemos antes para o reino do transcendente, do poético, do vago" (ROSA, 2003, p. 113); ou, referindo-se ao aspecto "documentário" do Corpo de Baile, diz: "[...] é apenas subsidiaríssimo, acessório, mais um 'mal necessário', mas jamais devendo predominar sobre o poético, o mágico, o humor e a transcendência metafísica" (ibidem, p. 123).

Há, ainda, a famosa "valoração" que o escritor dá aos aspectos de sua obra, sendo que vale a pena citá-la por inteiro:

\footnotetext{
Por isto mesmo, com apreço de essência e acentuação, assim gostaria de considerálos: a) cenário e realidade sertaneja: 1 ponto; b) enredo: 2 pontos; c) poesia: 3 pontos; d) valor metafísico-religioso: 4 pontos. Naturalmente, isso é subjetivo, traduz só a apreciação do autor, e do que o autor gostaria, hoje, que o livro fosse. Mas, em arte, não vale a intenção. (ibidem, p. 90-1)
}

Impossível querer retraçar uma espécie de motivação única e determinante para a escolha dessa tradução por parte de Guimarães Rosa. Interessante notar também que o fato de o original em inglês ser mais "convencional" do ponto de vista da linguagem, e, além disso, pretender-se referencial e "verdadeiro" - por vias de um credenciamento do literário a partir de boletins científicos -, não implica a incapacidade de ele alçar voo ao plano metafísicoreligioso, intento confesso de Rosa para seus escritos. Afinal, em seu cerne e temática, Last of the Curlews trata, sim, de questões transcendentais, tais como a alteridade frente ao animal, a ética e o destino humano.

\section{Texto}

E, se é possível supor que João Guimarães Rosa assume um compromisso ao escolher verter uma obra que flerta com a cientificidade e com o engajamento político, isso não incorre necessariamente em privilégio, na tradução, do "conteúdo" frente à "forma" (se se pensar a partir dessas categorias). Rosa concede a seus tradutores, por exemplo, uma série de liberdades:

A orientação válida é mesmo aquela - de só pensarmos nos eventuais leitores italianos. Não se prenda estreito ao original. Voe por cima, e adapte, quando e como bem lhe parecer. (ibidem, p. 99-100) 
Evidentemente que se trata de tipos de texto muito diferentes. Na citação acima, Rosa se refere a Cara de Bronze, do Corpo de Baile, de ímpar radicalidade estrutural e linguística, bem diverso de Last of the Curlews. De toda maneira, percebe-se no escritor mineiro, como se notará a seguir, um inflexível senso de responsabilidade para com a excelência textual e de pensamento, parecendo impossível o cenário em que ele publicasse algo sem o máximo rigor de execução.

Na série de crônicas Rosa em três tempos, de Manuel Bandeira, já citada aqui, o escritor pernambucano discorre sobre o árduo processo de reescrita de Guimarães Rosa não apenas em seus textos planejados enquanto obras (componentes de seu corpus literário, entenda-se), mas em qualquer peça que previsse publicação. Logo após o trecho em que comenta os esforços de Rosa na feitura de O Último dos Maçaricos, ele expõe seus pensamentos acerca das contribuições que o escritor mineiro dava ao jornal $O$ Globo:

No caso de $O$ Globo deve estar sucedendo o mesmo. Escrever para jornal é como escrever na areia. Rosa não escreve na areia: Rosa grava na pedra. Para a eternidade. Assim, o que Rosa está fazendo em $O$ Globo é, capítulo a capítulo, mais um livro, digno de ficar junto de Sagarana, Corpo de Baile e Grande sertão: veredas. (BANDEIRA, op. cit., p. 320)

Dado esse cuidado com o texto literário, pode-se perceber um conjunto de expedientes adotados por Rosa de modo a fortificar a dimensão poética do texto de origem quando passado ao português, seja por meio de um escopo vocabular mais alargado e sortido do que o do original, ${ }^{\text {ix }}$ seja por meio de cortes, inversões e utilização constante de aliterações e ritmo. Tal método tanto serve para manter processos técnicos existentes no romance em inglês quanto para criar procedimentos poéticos que não havia. A escolha dos trechos a seguir busca contemplar, por amostragem, alguns desses momentos.

Um dos aspectos que mais se destaca ao cotejar original e tradução é a variação vocabular que Rosa emprega em termos repetidos próximos. Há no original, por exemplo, a incidência da palavra wave quatro vezes em dois parágrafos seguidos, sendo que em duas ocasiões o substantivo é acompanhado do adjetivo great (BODSWORTH, 1955, p. 470-1). Na tradução, constam, nos mesmos trechos, vaga, onda, onda grande e vagalhão (BODSWORTH, 1958, p. 450) - ambas as últimas se referindo a great wave.

Tal atitude de buscar sinônimos - quando a repetição é considerada gratuita - é aconselhada por ele a seu tradutor alemão ao menos duas vezes: 
I. - Nas linhas 3 e 7, há duas vezes a palavra "nämlich". Não ficaria melhor, se possível, evitar-se a repetição?

$[\ldots]$

IV. - Linhas 9 e 6 (de baixo). Vejo: "Es steht fest" e "Händen fest". Evitar a repetição, tão perto? (ROSA, op. cit., p. 310-11)

Segue mais um exemplo do original condensado:

The female bobbed up and down jerkily and a low, muffled quirking came from deep in her throat. The male bobbed and answered softly. For a minute they stood almost motionless, eying each other, bobbing occasionally. (p. 476, grifos nossos)

Pode-se perceber o uso repetido do verbo bob, construindo o sentido e a imagem do movimento em cortejo entre macho e fêmea. Para o mesmo trecho, na tradução, Rosa escolhe três soluções diferentes para a mesma palavra:

A fêmea se meneou, para cima e para baixo, às sacudidelas, e um cacarejo baixo, abafado, veio-lhe do fundo da garganta. O macho bamboleou-se, e respondeu, arrulhante. Por um minuto quedaram, quase imóveis, olhando um para o outro, trejeitando de vez em quando. (p. 456, grifo nosso)

Uma última amostra de tal procedimento permite abordar tangencialmente outro aspecto da tradução. A expressão shore birds é largamente utilizada no romance, sendo um termo técnico para pássaros encontrados em linhas costeiras, na presença de areia ou lama. Rosa traduz de maneira igualmente técnica, mas sempre buscando a variação: aves praieiras, aves limícolas e aves ripárias. (pp. 443, 442 e 443, respectivamente)

Talvez aí se justifique o volume de pesquisa e materiais pedidos pelo escritor a amigos. Os termos técnicos utilizados na obra não se restringem à ornitologia, mas englobam também vocabulário botânico, marítimo, aéreo, meteorológico e topográfico. A leitura de obras especializadas em português deve tê-lo permitido, conjuntamente ao seu já vasto repertório vocabular, trazer ao romance traduzido tal variedade léxica sui generis. Há somente uma nota de rodapé a fim de esclarecer um termo mantido em língua estrangeira no corpo do texto: "Muskeg: musgos, dos gêneros Sphagmum, Hypnum, etc.; musgos e juncos que cobrem certos pântanos, no Canadá e no Norte dos Estados Unidos". (p. 437)

Ao elogiar o trabalho de Edoardo Bizzarri, o vocabulário vário é uma particularidade a que ele se refere ao enumerar as virtudes que crê serem as de uma boa tradução: 
a riqueza vocabular, a agudez, a eficácia. Sempre, a poderosa lucidez. A inteligência. Você recria, reinsufla, remagnetiza, reimanta. (ROSA, op. cit., p. 166, grifo nosso)

Para fazer isso com sua própria tradução, Rosa lança mão de uma série de recursos poéticos, entre eles aliteração, assonância e ritmo. No exemplo a seguir, ainda no início do livro - "He set his wings and dropped down in a series of zigzagging side-slips" (p. 457-8); "Dispôs as asas e deixou-se descer, com uma série ziguezagueante de descaídas de lado" (p. 435-6) -, o autor canadense usa repetidas consoantes fricativas alveolares ([s] e [z]), tirando proveito do soar sibilante reiterado em um trecho que narra o voo do maçarico. Dispostos por todo o período, mas concentrando-se na parte final ("He set his wings and dropped down in a series of zigzagging side-slips"), tais sons também são escutados na tradução, aproveitando-se ainda da consoante palato-alveolar, igualmente fricativa, [S], de deixou-se: "Dispôs as asas e deixou-se descer, com uma série ziguezagueante de descaídas de lado”. E, além disso, Rosa expande uma segunda cadeia sonora, dessa vez de oclusivas alveolares vozeadas ([d], em “dropped down [...] side-slips"), compondo-a em toda a extensão frasal: "Dispôs as asas e deixou-se descer, [...] descaídas de lado".

Em outros casos, Rosa enriquece o texto melopaicamente mesmo onde não havia tal efeito: "[...] of an ice hemmed river half a mile below" (p. 457) por "[...] de um rio orlado de gelo, meia milha abaixo" (p. 435), em que há a reiteração do [h] e do [1] em "rio orlado de gelo"; a cadeia [w] e [于] ainda em "rio orlado de gelo [...] abaixo"; a aliteração do [m] e assonância entre [a] e [e] em "meia milha abaixo". Além disso, o trecho, separado por vírgula, é formado por uma redondilha maior e outra menor $\left(1^{\mathrm{a}} \cup-/ / \cup-/ / \cup \cup-/ /\right.$ e $2^{\mathrm{a}}-\cup$ $/ /-\cup / /-)$, conferindo-lhe musicalidade.

Ao verter o romance para o português, Guimarães Rosa também se utiliza de alguns outros artifícios para cadenciar mais a linguagem no idioma de chegada, tais como: dividir um parágrafo em dois; juntar e separar períodos; adicionar travessão, dois pontos e ponto e vírgula; intercalar orações; inverter elementos da frase etc.

No trecho do original a seguir, por exemplo, há dois períodos em ordem direta. Na tradução, Rosa mantém a estrutura do primeiro, mas desloca o sintagma adverbial no segundo:

The snow melted from their feathers and the curlew led his flock into a sharp climb. The pain and the fatigue drained quickly from their wings and breasts with normal flight. (p. 471)

A neve se desfez de suas penas, e o maçarico levou o bando numa ascensão vertical. Com o voo direto, a fadiga e a dor logo se escoaram de suas asas e peitos. (p. 451) 
Neste outro exemplo, a mudança é mais significativa, e Rosa muda a ordem dos períodos dentro de um parágrafo, possivelmente por motivação do movimento narrativo:

\begin{abstract}
Far above him, the curlew could hear the faint, lisping notes of the migrants. Needles of ice began forming at the shallow edges of the mud-flat puddles. His instinct rebelled at flying alone, yet when he called shrilly into the cold night there was no answer, and the time had come when he had to move. (p. 464) Agulhas de gelo começavam a condensar-se nas beiras baixas das poças do charco. De lá de muito acima dele, atenuados pela distância, o maçarico podia ouvir os ciciados gritos dos arribadiços. Seu instinto se revoltava contra ter de voar sozinho; mas, quando ele piava, insistentemente, no frio da noite, não obtinha resposta. E chegou a hora em que precisou de partir. (p. 443)
\end{abstract}

É como se a frase descritiva - "Needles of ice [...]" / "Agulhas de gelo [...]" -, fosse contextualizadora do ambiente em que a cena se passa, apontando a mudança de temperatura e justificando o chamado do instinto migratório do pássaro. E, para tanto, Rosa a desloca para o início, passando o foco narrativo ao maçarico logo em seguida, em um movimento imagético contínuo e não intercalado.

No exemplo a seguir, o narrador descreve as figuras de tubarões que surgem quase à 66 superfície do mar enquanto os pássaros voam:

Day, when it came, was hot despite the wind. Occasionally the gray-blue form of a shark glided close to the sea's surface below them. (p. 472)

O dia, quando veio, veio quente, apesar do vento. De vez em quando, debaixo deles, deslizava, quase à superfície do mar, a forma azul-cinzenta de um tubarão. (p. 452)

No original, o sujeito "the gray-blue form of a shark" vem logo após o advérbio occasionally, ocupando a posição dois da oração. Na tradução, o sujeito "a forma azulcinzenta de um tubarão" é deslocada para a última posição, de maneira que a composição da imagem mental à medida em que se lê é feita progressivamente, num crescendo de suspense, que finda com a figura principal do predador.

Nas duas amostras abaixo, períodos únicos são divididos por meio de ponto final, como que conferindo mais impacto às afirmações:

But the feeding was poor and, thought the next day was very hot, the curlews flew again. (p. 481)

Mas o alimento era parco. E, embora o outro dia fosse quente, os maçaricos revoaram. (p. 462)

$[\ldots]$

There is no evidence of disease or failure of food supply. No, there was only one cause: slaughter by human beings, slaughter in Labrador and New England in 
summer and fall, slaughter in South America in winter, and slaughter, worst of all, from Texas to Canada in the spring. (p. 474)

Sabe-se que não aconteceu doença alguma aniquiladora, nem carência de alimento. Não. Houve apenas uma causa: a chacina, por seres humanos. Massacre na Nova Inglaterra e no Labrador, outono e verão, morticínio na América do Sul, no inverno, e, pior de todas, a matança, do Texas ao Canadá, na primavera. (p. 454) ${ }^{\mathrm{xi}}$

Outro recurso, esse bem menos usado - apenas duas vezes em toda a tradução - é a de supressão de trechos inteiros. No primeiro parágrafo, é suprimido: "In the five hundred miles of tundra he had flown over that night, there had been many rivers with identical twists, yet the curlew knew that now he was home" (p. 457). Já no meio no romance, é suprimido ainda: "He started home, drifting slowly from mud flat to mud flat. In a week he was two hundred miles northward" (p. 475).

Talvez se possa pensar a razão dos cortes a partir de certas recomendações de Rosa a Curt Meyer-Clason: "No $1^{\circ}$ parágrafo, cortar fora o 'São Francisco'. [...] Sempre é melhor explicar menos e deixar a frase mais intensa, concentrada, forte" (ROSA, 2003, p. 241). Se o escritor se refere ao nível da frase, pode-se sem prejuízo ampliar tal orientação ao âmbito do parágrafo, do capítulo ou mesmo da obra por inteiro. De toda maneira, o caráter "dispensável” dos trechos suprimidos não se mostra de modo evidente, e a causas deveriam ser melhor investigadas. ${ }^{\text {xii }}$

Outro ponto a se levar em conta é a variabilidade da dicção ou do registro nos quais diferentes linguagens operam dentro do texto e de como essa oscilação foi transposta ao português - como já dito, o romance alterna narrativa e boletins científicos. A seguir, citados mais longamente, em contraste, trechos de ambas as naturezas. Em primeiro lugar, um relatório do Comitê de Proteção dos Pássaros:

Report of the Committee on Bird Protection to The American Ornithologists' Union, 1939-1940, on its inquiries into the current causes of depletion of our bird life.

[...]

It is of course possible that the Eskimo curlew is extinct, but a few reports of its existence during the past decade lead one to hope that it has been merely overlooked by observers. It would seem advisable, however, to attempt to establish relationships in Argentina. If curlews were found to be wintering in that country, steps might be taken to assure better protection. (p. 480)

Relatório do Comitê de Proteção dos Pássaros, 1939-1940, à União dos Ornitologistas Americanos, sobre suas investigações acerca das causas gerais do empobrecimento da avifauna.

$[\ldots]$

É possível, naturalmente, que o maçarico-esquimó já esteja extinto; mas algumas, poucas, informações de sua existência, na última década, dão-nos a esperança de que os observadores o tenham apenas despercebido. Conviria, contudo, tentar estabelecer contatos, a esse respeito, na Argentina. Se se encontrarem maçaricos 
invernando naquele país, medidas poderiam ser tomadas para melhor assegurar sua proteção. (p. 461)

Abaixo, diferindo sensivelmente da passagem supracitada, um trecho narrativo de acentuada carga poética:

They flew close together, the male always leading, the female a foot or two behind riding his air vortex. They talked constantly in the darkness, soft lisping notes that rose faintly above the whistle of air past their wings, and the male began to forget that he had ever known loneliness. (p. 478)

Voavam muito juntos, o macho sempre guiando, a fêmea a um pé ou dois atrás, amparando-se no remoinho de ar por ele causado. Conversavam na escuridão, constantemente, meigos ciciados pios, que débeis se faziam ouvir por sobre o aéreo zunido empós de suas asas; e o macho começava a esquecer-se de que algum dia houvesse conhecido a solidão. (p. 458)

Percebe-se que a mudança de tom permanece em português, no caso do relatório, pela manutenção do registro lexical técnico e denotativo, assim como das construções lógicas pertencentes ao gênero textual em questão, como em: “[...] sobre suas investigações acerca das causas gerais do empobrecimento da avifauna [...]" ou "[...] Conviria, contudo, tentar estabelecer contatos a esse respeito [...]”. Já na narrativa, é frequente o uso de figuras de linguagem e de um uso vocabular característico, pertencente a um registro outro, explorando imagens e sons: "[...] meigos ciciados pios, que débeis se faziam ouvir por sobre o aéreo zunido empós de suas asas [...]".

\section{Considerações finais}

Há como que um duplo compromisso implicado nessa tradução: um, à precisão terminológica, científica, ao uso da linguagem e da literatura como veículo de uma afirmação política que diz respeito às questões éticas frente ao animal e à destruição do patrimônio natural pelo ser humano; outra, à poesia, ao metafísico-religioso. Não se tratam de compromissos opostos, porém. Como já questionado aqui, em que medida essas questões ético-políticas também não fazem parte do que Rosa chama de metafísico-religioso? A própria obra do escritor atesta a essa amálgama, na qual o intangível convive com o tangível, o transcendental com o documental. Compromissos não de todo excludentes, mas absolutamente vinculados.

Com o objetivo de ser apenas uma primeira aproximação a $O$ Último dos Maçaricos, todos os temas aqui explorados fazem jus a uma investigação mais rigorosa e a uma análise mais longa, imprópria ao formato de artigo. Há, claro, aspectos que não foram desenvolvidos 
aqui. A título de exemplo, o modo como a tradução de trechos descritivos do comportamento do pássaro-protagonista opera um deslocamento significativo da concepção do animal enquanto ser, como se de um fisiologismo a um tratamento mais complexo, anímico, e por vezes próximo da consciência e da linguagem tal qual concebemos para humanos. ${ }^{\text {xii }}$ Como diz Rosa: "Vaca tem alma. Todo bicho tem alma. [...] (Com isto, estou elevando o instinto)" (ROSA, 2003, p. 313).

Além disso, a contextualização de Last of the Curlews na obra de Bodsworth e o lugar que ele ocupa na literatura de língua inglesa podem e devem ser explorados, assim como sua poeticidade própria, seu procedimento narrativo e sua linguagem. A descrição e análise das ilustrações que compõem tanto as edições originais (completas ou condensadas) quanto a publicação brasileira também devem ter seu lugar em uma pesquisa mais aprofundada e de maior extensão.

É possível pensar que, talvez, ao estudo da tradução do romance, se valha melhor um trabalho em grupo - uma espécie de força-tarefa multidisciplinar - a esforços individuais. Como dispensar conhecimentos vários ao se debruçar seriamente sobre um livro que, para além de todo o aparato técnico científico presente no original, procura constantemente alçar voos poéticos no tratamento plástico da língua quando vertido ao português? Espera-se que se tenha demonstrado quão válido e frutífero pode ser o estudo dos feitos de João Guimarães Rosa tradutor, e que surjam mais pesquisas acerca desse e de outros textos de mesmo caráter, assim como sobre a relação deles para com sua obra dita própria.

\section{REFERÊNCIAS BIBLIOGRÁFICAS}

\section{Material Online}

Catálogo Eletrônico do Arquivo João Guimarães Rosa: <http://www.ieb.usp.br/catalogo_eletronico/>. Acesso em: 14/12/2015, às 14h30. Entrevista concedida por João Guimarães Rosa a Pedro Bloch em 1963: <http://www.tirodeletra.com.br/entrevistas/GuimaraesRosa.htm>. Acesso em: 13/12/2015, às $10 \mathrm{~h}$.

$O$ Último dos Maçaricos, tradução de João Guimarães Rosa: $<$ http://www.literaturabrasileira.ufsc.br/documentos/?action=download\&id=6252>. Acesso em: 14/12/2015, às $14 \mathrm{~h} 40$.

Reader's Digest Condensed Books: volume 23, 1955: $<$ https://archive.org/details/readersdigestcon23plag>. Acesso em: 13/12/2015, 11h30. 


\section{Artigos}

FIGUEIREDO, Luiz Fernando de Andrade. João Guimarães Rosa e suas aves: era ele um observador de aves?. In: Atualidades Ornitológicas On-line No 153 - Janeiro/Fevereiro 2010. Disponível em: 〈http://www.ao.com.br/download/ao153_33.pdf >. Acesso em: 13/12/2015, às $12 \mathrm{~h}$.

\section{Livros}

BANDEIRA, Manuel. Rosa em três tempos. In: Andorinha, Andorinha. Rio de Janeiro: José Olympio, 1966.

BERMAN, Antoine. Pour une critique des traductions: John Donne. Paris: Gallimard, 1995.

BODSWORTH, Fred. Last of the Curlews. Berkeley: Counterpoint, 1995.

, Fred. Last of the Curlews. In: Reader's Digest Condensed Books: volume 23, Autumn, 1955 selections. New York: Reader's Digest Association, 1955.

Fred. O Último dos Maçaricos. In: Biblioteca de Seleções: Seleções da Reader's Digest, vol. VI. Tradução de João Guimarães Rosa. Rio de Janeiro: Editora Ypiranga, 1958.

70 MONTELLO, Josué. Diário da manhã, entrada do dia 7 de maio de 1957. In: Diário Completo, volume 1. Rio de Janeiro: Nova Aguilar, 1998.

ROSA, João Guimarães. Correspondência com seu tradutor alemão Curt Meyer-Clason (1958-1967). Rio de Janeiro: Nova Fronteira: Academia Brasileira de Letras; Belo Horizonte: Ed. da UFMG, 2003.

João Guimarães. Correspondência com seu tradutor italiano Edoardo Bizzarri. Rio de Janeiro: Nova Fronteira, 2003.

ROSA, Vilma Guimarães. Relembramentos: João Guimarães Rosa, meu pai. Rio de Janeiro: Nova Fronteira, 2014.

\footnotetext{
i Pedro Guilherme Bastos MENEZES - Graduado em Comunicação Social - jornalismo (2013) pela Universidade de Brasília.

Currículo Lattes Pedro Guilherme Bastos Menezes. Disponível em: http://lattes.cnpq.br/6292263267128325

ii Disponível em: <http://www.tirodeletra.com.br/entrevistas/GuimaraesRosa.htm>. Acesso em: 13/12/2015, às $10 \mathrm{~h}$.

iii A partir de pesquisa no Catálogo Eletrônico do Arquivo João Guimarães Rosa, no Instituto de Estudos Brasileiros (IEB) da USP, travou-se contato com documentos que atestam traduções de Rosa do poema Mulholland's Contract, de Rudyard Kipling, e dos contos Dust on the Big Hat, de S. Omar Barker, e Bad Penny, de B. M. Bower Wyoming. Códigos de referência para detalhes dos documentos: JGR-M-16,09, JGR-M-16,59, JGR-M-16,60 e JGR-M-16,61. Disponível em: <http://www.ieb.usp.br/catalogo_eletronico/>. Acesso em: $14 / 12 / 2015$, às $14 \mathrm{~h} 30$.

iv Em FIGUEIREDO, 2010, o autor utiliza uma série de nove critérios para enquadrar João Guimarães Rosa na categoria de "observador de aves", como: "interesse pelas aves", "leituras sobre aves", "conhecimento dos nomes das espécies", "conhecimento da biologia das espécies", "elaboração de listas de aves", entre outros.
} 
${ }^{v}$ Documento consultado no acervo digital do IEB, código de referência JGR-CTC-01,39. Acesso em: 14/12/2015, às $14 \mathrm{~h} 45$.

vi Código de referência: JGR-M-23,01. Informações obtidas por meio de pesquisa eletrônica do acervo. Acesso em: 14/12/2015, às $14 h 50$.

vii Mas também, é claro, a partir de sua obra literária: em FIGUEIREDO, 2010, é fornecida uma tabela - que se estende por 6 páginas - contendo os nomes populares de aves utilizadas por Rosa em seus livros, os correspondentes nomes científicos de cada espécie (conjeturados, em alguns casos), assim como as estórias particulares nas quais figuram.

viii Fred Bodsworth, autor do livro, foi presidente da Federação de Naturalistas de Ontário e emprega em seu livro um forte tom denunciador da extinção premente da ave.

${ }^{\text {ix }}$ Há de se ter em mente que a variedade vocabular e a sinonímia não necessariamente implicam em "força poética" - trata-se, porém, como veremos, de diretrizes que Rosa aconselha a seus tradutores.

" Tal cadeia sonora depende da variante do português brasileiro que se tem por parâmetro: os dês de "dispôs", "de" e "descaídas" podem ser pronunciados como [d3] - de toda maneira, se for o caso, tratar-se-ia de consoantes africadas pós-alveolares vozeadas, criando uma outra série de sons similares e contribuindo ainda assim para musicalidade do trecho.

${ }^{x i}$ Notar ainda a adição do adjetivo aniquiladora - relativo a doença - inexistente no original (procedimento de rara ocorrência no resto da tradução) e o uso de vários sinônimos para slaughter, repetido quatro vezes no inglês. xii Poder-se-ia, por exemplo, cotejar a versão publicada com o original datiloscrito existente no Arquivo João Guimarães Rosa a fim de verificar se houve alguma supressão no processo de edição. Uma leitura não dupla, mas tripla - levando em conta também o romance completo e problematizando seu processo de condensação -, pode igualmente apontar uma resolução e abrir, inclusive, novas possibilidades de análise da obra, visto que, como já exposto, o escritor fez questão de dispor da edição completa.

xiii "And every year he had looked back and even his slow-working brain could marvel at the endurance of his own wings." (p. 480, grifo nosso) / "E cada ano ele olhara para trás; e mesmo o seu cerebrozinho menino podia pasmar-se da pertinácia de suas próprias asas." (p. 460, grifo nosso)

RECEBIDO EM: 29 de junho de 2016

ACEITO EM: 6 de novembro de 2016

PUBLICADO EM: Dezembro de 2016 